\title{
Research on English Education and Teacher's Identity Xue Han
}

Department of Public Foreign Language Education, Beihua University Ji Lin, 132000

\begin{abstract}
In the education field, the self-identity of English teacher which is called self-identity of occupation is very important. Doing research on college English education and teachers' identity can effectively understand the teacher's teaching concept and teaching behavior. Meanwhile, by actively exploring English education and teachers' identity, summarize related factors influencing the English teachers' identity, then further let the teachers make their professional identity correctly towards positive factors in education; finally make good guidance to improve professional ability of education, which has an important and practical significance.
\end{abstract}

Keywords: English education; Colleges; Teacher's identity; Influential factors

\section{英语教育与教师身份认同探究}

\author{
韩 雪 \\ 北华大学公共外语教育学院, 吉林吉林 132000
}

摘要：在教育领域内，英语教师对于自身的身份认同即职业自我认知是十分重要的。进行相关的高校英语教育与教师 身份认同研究, 能够有效的了解到教师的教学理念以及教学行为。同时, 通过积极的探究英语教育与教师身份认同的情况, 总结出影响英语教师身份认同的相关因素, 进而让教师对于自身的职业正确的认同朝着教育积极因素进行转化, 最终为提升 教育专业能力作出良好的指导, 具有重要的现实意义。

关键词: 英语教育; 高校; 教师身份认同; 影响因素

中图分类号：H319 文献标志码：A

引言

身份一词用英语单词表达成 “identity”, 主要的含义就是指身份, 但是很多学者也普遍的认为这一 词也涵盖了身份认同的意思。对于身份认同而言, 所具有的意义更深刻, 也就是指对于自我的认知。伴随 知识的不断更新以及进步, 学者认为在社会中的不同群体以及不同层次, 或者不同的职业, 均需要相应的 身份认同, 而这种认可往往可以在社会心理学的层面有所涉及, 所以对于身份认同的研究是值得深刻挖掘 思索的。

\section{1 英语教师教育与教师身份认同相关概念阐述}

\section{1 英语教师教育}

英语教育是一个统指, 即个体进行学习教授语言的活动、经历以及过程的总和。同时, 教师教育主要 是指个体学习活动以及教授语言的专业领域, 并且涵盖了三项重要的术语, 分别为教师培训和教师发展、 教师教育。所以有学者通过分析及研究得出英语教师教育的定义主要是指: 英语教师学习教授英语的全部 内在活动以及外在活动的总和。同时，教师职前培养、职后培训也是包含的两个重要方面内容。

\section{2 英语教师身份认同}

英语教师身份认同在最初的阶段是心理学领域所探究的课题，身份认同为个体动态形式的心理认同， 
涵盖了个体对于自身身份的明确; 个体对于其归属群体的认知过程, 和与之相伴的一种具体情感的体验经 历以及行为模式的整合。在 1997 年, 由 Casanave and Scheeter 进行发表相关的教师身份认同研究的结 果以后, 在教师教育研究领域内, 逐渐的开始重视起教师身份认同的探究, 并且将其作为研究的重点方面。 之后研究的重点理论拥有英语教师专业发展核心论、教师决策决定说等。

\section{2 英语教师身份认同分析的重要性}

教育领域内, 教师针对自身职业的自我认知发挥的重要性突出。学者 Bullough 提出了以下的观点: 在教师教育期间, 教师认同至关重要, 能够作为意义以及决策的重要基础。同时对于教师的教育而言, 应 该从教师的自我认同角度开始探究。

教师身份认同感为伴随自身长期的实践工作，对于教学工作的价值以及性质等构建起的肯定和认可 感。教师身份认同包含的方面诸多, 例如对于教学工作展示出的积极性、教学期间所投入的热情、对于教 育职业产生的满意度以及对于自身职业角色的肯定程度等内容。

近些年来，由于身体状况、社会以及家庭等方面的原因，很多高校英语教师的工作会产生一定的影响。 所以，于不同时期的教育职业生涯阶段内，不断的展开自我评价以及反思，帮助高校英语教师建立起正确 的、积极向上的身份认同感是十分重要的内容。在对于自身具有正确的职业认同感情况下，能够让教师将 此转变为教学积极因素, 进而有效的增强教育专业技能。一旦教师长期的处在外部评价以及自我评价的相 对矛盾环境下，在出现自我素质以及时代挑战失去协调期间，便可以对于教师自身的价值、成就感造成疑 惑、否定现象, 所以教师很容易产生自我的不认同感, 进而对于职业认同感造成负面影响。鉴于此种形式, 不断的分析及探究高校英语教师身份认同现实状态, 将其纳入到重要的地位, 有利于认清影响到教师身份 认同的重要因素, 进而提出有效的策略, 指导教师在不同的时期积极的应对困难和挑战, 调整好自我心态, 积极创建起持久的良好教师身份认同感。

\section{3 英语教师于不同阶段表现出的身份认同情况}

对于教师身份认同而言，在全部的教育职业生涯内均具有涉及，总共具有五大阶段，分别为入职阶段、 稳定阶段、实验及重估阶段、平静及保守阶段、退休阶段，下面展开详细的分析。

首先, 在入职阶段: 这一时期也就是初次的作为教师的阶段。在这一过程中, 教师通常担任着入职三 年内的初任教师角色, 不仅承担着来自于自身的压力, 而且也要承担源自学生方面的压力。在学生的认可 方面, 以及对于经验的积累, 都需要一定的时间过程慢慢构建。因此, 在入职的阶段, 是建立起正确的教 师职业认同的重要前提基础时期; 其次, 在稳定阶段: 这一时期的教师通常已经具有四年到六年时间的工 作经历, 并且其基本上已经具有正确的职业认同, 对于自身工作方面上的压力能够自行的调节, 拥有渐渐 成熟的思想。虽然如此, 在此阶段中教师也会容易遭遇情感、家庭等方面因素的影响; 再次, 在实验和重 估阶段：在这一时期，具有相对较长的持续时间，工作的经历至少超过七年，并且在二十五年以下。通常 着这一阶段的教师因为教学工作时间长、教学经验丰富, 所以可以针对自身专业能力、教学的方式中表现 出的突出问题进行有效的调整, 通过采取科学有效的举措展开自主的自我评估; 接下来, 为平静以及保守 阶段：教师通常教龄超过二十六年, 并且在退休年龄以下。处于这一时期的教师, 具备了更加丰富以及成 熟的教学经验以及能力, 同时详尽的掌握住在学生的角度上所普遍认可的教学方式。拥有趋于平和的心理 状态, 即使工作期间出现新的冲击, 也不会因此构成较大波动和影响; 最后, 在退休期阶段: 主要为工作 
时间超过三十四年的教师人群。在这一时期, 教师通常具有身体方面的压力, 以及退休的压力等, 所以也 应该做好积极良好的心理整顿。

\section{4 影响英语教师身份认同的因素}

大量的调查研究表明, 能够影响到英语教师身份认同的因素众多, 主要是体现在以下的几方面，即教 师的专业能力、教师针对于自身职业的满意程度、教师的职业目标以及职业理想、教师的职业评价、学生 观等。

\section{1 英语教师的专业能力}

对于高校英语教师而言, 其自身的专业能力会对表现出的认同感具有极其重要的影响作用。即教师自 身对于专业能力水平高低的认知, 可以出现将专业能力不断提升的愿望, 并且也能够作为产生职业认同感 的重要产物。英语教师通过对于知识的不断探索, 能够在此期间增加职业认同感。而专业的英语教师, 通 常职业认同感会更高，可推动其更加满意职业，增加精力投入到工作中，并且愿意采取新型的教学方式以 及教学理念。所以, 将培养国家栋梁为己任的教师, 通常提出更高的专业能力要求, 进而职业认同感更加 强烈。

\section{2 教师的职业满意度}

伴随知识和经济全球化的不断深入推进，当前国内教师也相对的了解到国外教育工作者的待遇情况， 并且也能够掌握一定的工作环境以及薪酬待遇等情况。虽然近些年来, 国内教育工作者发生了良好的改善 待遇转变, 但是纵观比较其他的职业, 还处于较低的水平状态中, 教师的付出同回报之间比例不协调的情 况还存在。所以, 对于工资待遇满意程度不高, 能够对教师对于自身工作认同感产生较为直接的影响, 并 能够影响到专业能力提升的意愿。此外, 提升职业满意度同教师的工作环境之间也具有重要的联系, 在具 备齐全的教学工具、温馨舒适的教学环境下, 能够让教师具有更多教学理念的实践, 并且保持心情的愉悦 舒畅。同时, 网络平台的发展以及应用, 可以加强教师同学生之间的交流, 推动教学能力的提升。此外, 较高的社会福利可以将教师对于自身职业的满意度有效提升。

\section{3 职业理想和职业目标}

教书育人为一种崇高事业，在教师将这一职业看作为赚钱的铁饭碗，并非终身奉献事业的情况下，就 很容易因金钱诱惑使得工作的动力减弱，不能保有正确的职业理想，也就不可以实现将自身提升至新的思 想境界内, 同时加之外在条件的不满意, 对于工作热情度造成较为严重的影响。在教育工作期间, 构建起 积极的职业理想能够推动教师于低谷时期以及困难阶段具有坚毅的性格、良好的心理素质应对以及解决各 种难题。因此, 对职业认同感造成重要的影响因素之一就是职业理想; 此外, 教师也应该建立起具体的职 业发展目标, 高校也应该帮助英语教师对于职业目标进行明确, 设计科学的职业规划。只有具备了明确的 职业目标以后，才能够良好的减少因教育目标无边界性造成不必要的影响或者伤害，并且能够在繁重的教 学工作面前采取积极的应对举措, 勇敢的朝着目标前进。同时拥有了具体的发展规划以及方向、目标, 也 有助于教师获得教育主观意识, 进而增强职业荣誉感以及归属感。

\section{4 教师的职业评价}

教师的职业评价来源渠道诸多, 具体涵盖了三大方面的内容, 即自我反思、同行的评估以及学生的评 价。 
首先, 教师的自我反思能够显著的将教学专业水平进行提升, 是一种有效的激励举措。展开自我的反 思期间, 教师能够将自身教学的经验进行不断的积累, 总结教学不足之处, 为建立起更好的教师形象, 加 强自身素质以及修养的提升。其次，同行的评价就是指教师同教师之间实施的评价。教师可经互相的听课 或者相互展开公开课等途径, 在同事之间把自身的教学方式进行展示。在同事之间经归纳、讨论以及总结, 相互评价教学的能力、对于知识的应用能力等。最后, 学生的评价也是至关重要的影响因素, 可以对于教 师的职业生涯发展构成深远影响。在学生对教师进行评价时, 教师通过将此作为基础依据对于学生的现实 学习需求进行掌握, 进而成为一名优秀合格的教师。进行评价时, 学生会着重从教师的教学能力以及职业 道德上考虑。所以, 学生对于教师的评价, 同教师职业认同之间存在紧密的联系。如果评价结果是积极的, 则能够帮助教师建立起足够的自信心，通过更加的努力进取获得更多肯定；而消极的评价结果，能够帮助 教师深刻认清自身具有的不足问题，通过整改符合标准。

\section{5 学生观}

学生是教师的教育对象，教师进行授课不光是为了进行答疑解难，片面的增加学生知识含量，同时也 要重视将学生学习能力以及社会的实践能力进行提升, 进而帮助其构建正确的价值观。同时, 教育者对学 生产生积极的影响也是最大的实践价值。学生可以在日常的同教师接触中发觉到对学生的喜爱情感, 所以 学生也能够做出同样的情感回报。但是如果教师的工作散漫、解急，不仅自己具有消极的人生态度，对于 学生而言也不会产生积极的影响作用, 应该避免此种工作状态。所以, 教师也要重视起形成正确的学生观, 将学生作为朋友对待, 愿意帮助学生并为之付出努力, 形成平等的关系, 摆正自身位置, 以学生角度分析 出自身存在的问题，最终获得较高的身份认同。

\section{5 建立起英语教师身份认同的教育策略}

\section{1 职前培养}

\section{2 职后培训}

教师身份认同作为持续性的发展过程，需要职前培养以及职后培训具有完整性的衔接。而教师应该紧 跟时代发展的步伐, 在虚拟教师集体, 过渡到真实教学环境内, 良好的融入进真实的教师集体，只是凭借 前期师范教育对学生进行灌输的对于教师职业的认知是远远不够的。通过采取突出师范继续教育的举措, 可以针对非师范生从事教育工作创建更多的学习机会, 进而增强教师职业归属感以及组织认同感，同时也 能够为师范生继续的从事教育事业建立起良好的外部条件, 构建合作型专业文化氛围, 进而推动教师具有 专业上的安全感以及认同感。

\section{6 结语}

教育工作是教师生命中重要的构成部分之一，在教师良好的掌握推动自身发展的外部积极因素并且将 消极因素进行摆脱以后, 就会认知教育不只是一种职责，同时也为一项快乐以及享受。教师自我成长期间， 身份认同是一种内在的动力, 可以帮助教师感知工作的意义，并寻找到工作的乐趣。拥有积极的身份认同 可以不断积累自身经验提升专业水平, 构建正确的职业理想以及目标, 肯定教学的价值, 最终形成职业认 同感，以及推动教师职业变为终身事业，享受工作产生的成就感。 


\section{参考文献:}

[1] 刘淑华, 周明杰. 大学青年教师身份认同现状及其影响因素分析 [J] 沈阳师范大学学报 (社会科学 版), 2016, (06) : 142-145.

[2] 王卓. 数字信息化环境下商务英语专业教师的身份认同危机研究 [J]. 安徽文学(下半月), 2016, (10) : 139-140.

[3] 周明杰. 大学英语青年教师身份认同形成的个案研究 [J]滩坊工程职业学院学报, 2015, (03):9-12+16.

[4] 高成. 学科教学论教师身份认同危机的成因及消解[J] 教师教育研究. 2015, (01) : 12-16+5.

[5] 张华. 影响高校英语教师身份认同的相关因素分析 [J]湖北广播电视大学学报. 2014. (11) :118-119.

[6] 寻阳, 孙丽, 彭芳. 我国外语教师身份认同量表的编制与检验[J]山东外语教学. 2014. (05) :61-67.

[7] 刘昕, 赵志勇, 娄国神. 高校英语教师身份认同及其影响因素分析 [J]黑龙江工程学院学报. 2014, (03) : 77-80.

[8] 梁琳. 运用隐喻探究湘西州高校英语教师专业身份认同发展[D].中南大学, 2013.

\section{References:}

[1] Liu Shuhua,Zhou Mingjie. Analysis on University Young Teacher's Identity Status and Their Influential Factors [J]. Journal of Shengyang Normal University (Social Science Edition), 2016,(06):142-145.

[2] Wang Zhuo. Study on Business English Teacher's Identity in the Digital Information Circumstance [J].Anhui Literature (2nd half month), 2016,(10):139-140.

[3] Zhou Mingjie. Case Study on Young College English Teacher's Identity[J]. Journal of Weifang Engineering Vocational College, 2015,(03):9-12+16.

[4] Gao Cheng. Causes and Digestion on the Crisis of Subject Teaching Theory Teachers[J]. Teacher Education Research, 2015,(01):12-16+5.

[5] Zhang Hua. Related and Influential Factors of College English Teachers' Identity[J]. Journal of Hubei Radio and Television University,2014. (11):118-119.

[6] Xun Yang, Sun Li, Peng Fang. Scale preparation and Inspection of China's Foreign Language Teacher's Identity[J] Shandong Foreign Languages Teaching Journal,2014.(05):61-67.

[7] Liu Xin, Zhao Zhiyong, Lou Guowei. The Related and Influential Factors of College English Teacher's Identity[J]. Journal of Heilongjiang Institute of Technology, 2014,(03):77-80.

[8] Liang Lin. Metaphor Method to Explore Suggestions on College English Teacher's Professional Identity Development[D]. Central South University, 2013. 